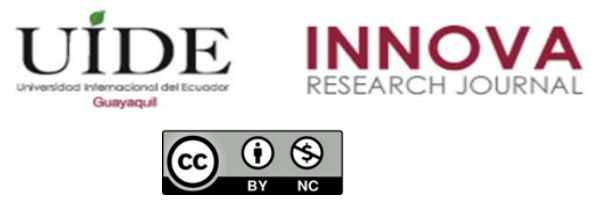

INNOVA Research Journal, ISSN 2477-9024

(Septiembre-Diciembre 2019). Vol. 4, No.3.1 pp. 89-107

DOI: https://doi.org/10.33890/innova.v4.n3.1.2019.1056

URL: http://revistas.uide.edu.ec/index.php/innova/index

Correo: innova@uide.edu.ec

\title{
Convivencia y comunicación escolar: Transformación desde la acción y la participación
}

\section{Coexistence and school communication: Transformation through action and participation}

Nanci Barrios Briceño

Jenny Andrea Quiroz Villacís

Universidad Espíritu Santo, Ecuador

Eli Marrero Castro

Universidad Nacional Experimental Francisco de Miranda, Venezuela

María Eugenia Gómez Naranjo

Universidad Pedagógica Libertador, Venezuela

Autor para correspondencia: nbarrios@uees.edu.ec; jaquiroz@uees.edu.ec

Fecha de recepción: 11 de julio de 2019 - Fecha de aceptación: 30 de septiembre de 2019

\section{Resumen}

La investigación tuvo como propósito Aplicar un Plan de acción dirigido a fortalecer la convivencia y comunicación en una institución educativa venezolana, a través de la Investigación Acción Participativa apoyada en el Paradigma Crítico. En la fase Diagnóstica, aplicando cuestionario y en grupo de discusión con estudiantes, docentes, administrativos, obreros y representantes surgió que los estudiantes tienen poco compromiso con sus responsabilidades académicas, falta de cooperación por parte de los representantes e incumplimiento de normas de convivencia. Realizada la jerarquización de necesidades y aplicada la matriz FODA, resultó abordar la convivencia escolar. La fase de Planificación y ejecución permitió organizar y aplicar las actividades. En las fases de evaluación y retroalimentación se obtuvo como resultado que hay disposición para cumplir con las normas de convivencia. Hubo amplia participación de los padres y se resaltó la necesidad de manifestarles amor a los hijos. En la convivencia estudiantil se evidenció la disposición de jóvenes que quieren vivir en una comunidad tolerante y segura. Se concluye que cada una de las actividades ejecutadas generó el compromiso de seguir trabajando en pro de una sociedad capaz y dispuesta a relacionarse respetando la individualidad del otro, desde una comunicación armónica en la convivencia escolar.

Palabras claves: convivencia; comunicación; armonía; contexto educativo

\begin{abstract}
The purpose of the research was to apply an Action Plan aimed at strengthening coexistence and communication in a Venezuelan educational institution, through Participatory Action Research supported by the Critical Paradigm. In the Diagnostic phase, applying a questionnaire and a group discussion with students, teachers, administrative staff, workers and representatives, it emerged
\end{abstract}


that students have little commitment to their academic responsibilities, lack of cooperation from representatives and non-compliance with coexistence rules. Once the hierarchy of needs was carried out and the SWOT matrix was applied, it turned out to address school coexistence. The Planning and execution phase allowed to organize and implement the activities. In the evaluation and feedback phases it was obtained as a result that there is willingness to comply with the rules of coexistence. There was broad parental involvement and the need to express love to the children was highlighted. In the student coexistence the disposition of young people who want to live in a tolerant and safe community was evident. It is concluded that each one of the activities carried out generated the commitment to continue working for a society capable and willing to relate respecting the individual's individuality, from a harmonious communication in school life.

Key words: coexistence; communication; harmony; educational context

\section{Introducción}

\section{Contexto de Estudio}

Para aquellos que conviven de una u otra forma en el sistema educativo es evidente la imperativa necesidad de transformar los espacios institucionales viciados de una crisis moral y estructural. Según Esté, (1995) la crisis se manifiesta en un alto índice de exclusión escolar, falta de pertinencia en los aprendizajes propuestos. Escaso rendimiento y poca disposición de docentes para crear y comprometerse en cursos de cambios, baja atención presupuestaria a las necesidades educativas.

En atención a lo anterior, el enfoque metodológico se circunscribió a la perspectiva de la Investigación Acción apoyado en el "Paradigma Crítico Reflexivo" que permite la aproximación al entorno social desde sus contradicciones y desigualdades, en la búsqueda de la esencia del problema, promoviendo la participación del colectivo en el estudio de sus situaciones no deseadas, así como de la planeación de propuestas de cambio, su ejecución y evaluación, mediante un proceso cíclico en espiral planificación, acción, reflexión y evaluación del resultado de la acción.

Es así, como siendo necesario un diagnóstico en todo proceso de investigación - acción, a partir del 1ro de septiembre se llevó registros de campo como instrumento de recolección de datos, así como aplicación de cuestionarios a colegas, personal administrativo y obreros, estudiantes y representantes.

De tal manera, que el presente diagnóstico tuvo como propósito: Identificar las situaciones educativas de la institución, así como explorar las propuestas de la comunidad educativa para abordar dichas situaciones.

En este sentido, cabe destacar que durante los días 16 - 17 y 18 de septiembre los docentes de la Unidad Educativa, ubicada en el Estado Aragua Venezuela, se congregaron en la biblioteca de la institución para discutir las situaciones del liceo, hacer propuestas de solución y organizarse en comisiones de trabajo para abordar las limitaciones. Algunos expusieron desde sus experiencias los aspectos que desearían mejorar en su entorno laboral y del proceso de enseñanza aprendizaje. 
Estos indicaron su inconformidad con el irrespeto hacia ellos, falta de apoyo y compromiso de los representantes, indisciplina, uso inadecuado de las horas libres, problema de conducta e incumplimiento de las normas de convivencia, así como la carencia de valores de los estudiantes; cada una de estas inconformidades fue registrada en una pizarra sin orden de prioridad. Otros docentes plantearon posibles soluciones a través de la lluvia de ideas, refiriendo que era necesario incentivar a los representantes a participar y supervisar la formación de sus representados.

Al ser suspendida la asamblea de representantes, los cuestionarios fueron enviados a los hogares con los representados para ser llenados en casa, la comunidad de informantes de dicho instrumento estuvo conformada por madres, padres y/o representantes de estudiantes de 2 do, 4to y 5to año de bachillerato. Los resultados de estos instrumentos arrojaron una visión externa al proceso educativo, pero igual de importante, estos refirieron como situaciones problema: El irrespeto a los docentes, el poco compromiso de los profesores con los estudiantes, las escenas románticas entre jóvenes dentro y fuera de la institución, la violencia y agresividad de los educandos, manifestado por los representantes con diferentes expresiones.

Desde otra perspectiva, los estudiantes exponen una inconformidad con el desorden en las aulas, las peleas entre compañeros, "los bochinches en el salón”, la apatía de muchos estudiantes, entre otros. De tal manera, que es evidente la indisciplina y falta de valores de muchos estudiantes, pareciera que los problemas de infraestructura son paralelos a los problemas de conducta de los educandos acompañados del poco compromiso de los representantes con el proceso formativo de sus representados. Una formula intolerante que atenta con el éxito de todo procedimiento formativo del adolescente.

A continuación, se presenta una matriz F.O.D.A de la institución objeto de estudio: 
Tabla 1.

Matriz FODA: U.E.N. “Creación Santa Rita I” Municipio: Francisco Linares Alcántara

\begin{tabular}{|c|c|}
\hline Fortalezas & Debilidades \\
\hline $\begin{array}{l}\text { • Directivo comprometido con } \\
\text { las mejoras institucionales. } \\
\text { • Personal obrero muy } \\
\text { colaborador y responsable } \\
\text { • Infraestructura apta en } \\
\text { relación con las necesidades de } \\
\text { espacio del plantel. } \\
\text { • Regularmente se hacen } \\
\text { asambleas de docentes para tomar } \\
\text { decisiones } \\
\text { • La asociación civil es } \\
\text { constante y participativa en las } \\
\text { actividades escolares } \\
\text { • Existe el programa mamá } \\
\text { arepa, el cual por la condición } \\
\text { económica de los estudiantes es muy } \\
\text { necesario. } \\
\text { • El personal docente, } \\
\text { administrativo y obrero conviven y } \\
\text { laboran en completa armonía. }\end{array}$ & $\begin{array}{l}\text { • Padres madres y representantes } \\
\text { poco comprometidos con el proceso } \\
\text { educativo de sus hijos. } \\
\text { • Cantidad considerable de padres } \\
\text { madres y representantes poco afectivos } \\
\text { con sus hijos o representados. } \\
\text { • Indisciplina de los estudiantes. } \\
\text { • Profesores poco motivados con } \\
\text { su práctica pedagógica } \\
\text { • Poco compromiso de los } \\
\text { educandos con su proceso educativo. } \\
\text { • Carencia de recursos didácticos } \\
\text { para la instrucción. } \\
\text { • Ausencia de filtros de agua para } \\
\text { los educandos. } \\
\text { • Laboratorio de biología sin } \\
\text { dotación de equipos y material. } \\
\text { • Insuficiencia de libros en la } \\
\text { biblioteca. }\end{array}$ \\
\hline Oportunidades & Amenazas \\
\hline $\begin{array}{l}\text { • La comunidad está } \\
\text { organizada. } \\
\text { • Existe una radio y una } \\
\text { televisora comunitaria (Teletambores) } \\
\text { en la localidad donde está ubicado el } \\
\text { plantel. } \\
\text { • Se cuenta con un módulo } \\
\text { policial en la misma calle. } \\
\text { • El N.A.P. de la comunidad } \\
\text { está a disposición del liceo. }\end{array}$ & $\begin{array}{l}\text { • Los focos de delincuencia } \\
\text { presentes en la comunidad. } \\
\text { • La inseguridad para estudiantes y } \\
\text { personal que labora en la institución. } \\
\text { • La conducta conflictiva de } \\
\text { algunos habitantes cercanos al plantel. } \\
\text { - Mal funcionamiento del drenaje } \\
\text { de las calles el cual atenta con el buen } \\
\text { desplazamiento de los automóviles. }\end{array}$ \\
\hline
\end{tabular}

Para el día 2 de octubre se convocó a una asamblea de docentes para llevar a consenso las dificultades de la institución. Manifestaron sus criterios en relación de la jerarquización de situaciones planteadas según los que ellos consideraban prioritarios. Como resultado de lo anteriormente expuesto, se presentan las situaciones educativas surgidas en el encuentro sin orden de prioridad: 
Tabla 2.

Matriz de Priorización de Situaciones Educativas.

\begin{tabular}{|c|c|c|c|}
\hline Problema & $\begin{array}{l}\text { Frecuencia } \\
\text { Absoluta }\end{array}$ & $\begin{array}{r}\text { Frecuencia } \\
\%\end{array}$ & Importancia \\
\hline Falta de cooperación de representantes & 8 & 13.33 & 3 \\
\hline $\begin{array}{l}\text { Poco compromiso del estudiante con sus } \\
\text { estudios }\end{array}$ & 6 & 10 & 4 \\
\hline Incumplimiento de normas de convivencia & 16 & 31.69 & 1 \\
\hline $\begin{array}{l}\text { Comportamiento inadecuado de los } \\
\text { estudiantes }\end{array}$ & 10 & 16.66 & 2 \\
\hline Carencia de valores en los estudiantes & 8 & 13.33 & 3 \\
\hline Agresividad estudiantil & 4 & 6.66 & 5 \\
\hline Mal uso de horas libres & 3 & 5 & 7 \\
\hline Inasistencia de docentes & 2 & 3.33 & 6 \\
\hline TOTAL & 60 & $100 \%$ & \\
\hline
\end{tabular}

En cuanto a la recolección de información los instrumentos aplicados contenían preguntas cerradas, policotómicas con cuatro opciones de respuesta (Muy buena, buena, regular y mala) y dicotómicas con dos opciones de respuesta, (Si, No). En relación a los análisis de las preguntas abiertas la tendencia de respuestas estuvo direccionada a la inconformidad con: La indisciplina y carencia de valores de los estudiantes, el incumplimiento de normas de convivencia y la falta de cooperación por parte de los padres con la educación de los representados, entre otras.

\section{Tabla 3.}

Distribución de respuestas emitidas por el personal docente, administrativo y obrero a los instrumentos aplicados. ¿Piensa usted que la convivencia de los estudiantes es?

\begin{tabular}{ccccccccc}
\hline Ítem & F.A & $\%$ & F.A & $\%$ & F.A & $\%$ & F.A & $\%$ \\
\hline 4 & MB & & B & & R & & M \\
& & 8 & 40 & 12 & 60 & & \\
\hline
\end{tabular}

Fuente: elaboración propia

En relación al instrumento dicotómico los resultados se presentan a continuación.

\section{Tabla 4.}

Distribución de respuestas emitidas por las madres, padres y/o representantes a los instrumentos aplicados. ¿Considera usted que una revisión y socialización de las normas de convivencia entre el personal de la institución, estudiantes y representes contribuiría a mejorar el entorno educativo de su hija, hijo o representado?

\begin{tabular}{ccccc}
\hline Ítem & F.A & \% & F.A & \% \\
\hline \multicolumn{3}{c}{$\mathrm{Si}$} & \multicolumn{2}{c}{ No } \\
18 & 90 & 2 & 10 \\
\hline
\end{tabular}

Fuente: elaboración propia 
En concordancia con los resultados obtenidos de la reunión de profesores, así como de los instrumentos aplicados a éstos y el personal administrativo, obrero, a estudiantes y representantes, se presentan seguidamente las situaciones que se consideraron relevantes por la frecuencia y énfasis de su aparición durante el diagnóstico, siendo éstas limitantes del proceso de enseñanza aprendizaje y factibles de ser solucionados con el recurso humano:

a) Incumplimiento de normas de convivencia.

b) Comportamiento inadecuado de los estudiantes.

c) Carencia de valores de los estudiantes.

d) Falta de cooperación por parte de los padres con la educación de los representados.

e) Poco compromiso de los estudiantes con sus estudios.

f) Mal uso de horas libres.

g) Inasistencia de docentes.

h) Agresividad estudiantil.

Según la matriz de priorización de situaciones educativas la situación que requiere mayor atención es el incumplimiento de normas de convivencia, lo que se desencadena una serie de conflictos y limitaciones en el proceso educativo que cumpliendo las normas se podría evitar. El aula sería entonces, un espacio para el encuentro de saberes y el tiempo en ella una oportunidad para aprender a convivir en armonía.

\section{Marco de acción y fundamentación}

En la actualidad existe sobre todo en el sistema educativo una preocupación acentuada por el tema de la pérdida de valores, siendo éste un fenómeno universal como resultado del mundo globalizado y desarraigado, los adolescentes viven en la búsqueda de éstos, solo que la falta de orientación les deja libertad de inclinarse por algunos que no le favorecen desde la óptica de nuestra moralidad social. Aún y cuando la sociedad ha llegado a la cima de los desarrollos científicos y tecnológicos, valores como la tolerancia y la convivencia han caído al fondo de la profundidad y parecen anacrónicos en la dinámica social.

Si señalamos el caso de los representantes debemos primero referir el artículo 54 de la Ley Orgánica de Protección a la Niña Niño y Adolescente. (LOPNNA 2009)

Los padres, representantes o responsables tienen la obligación inmediata de garantizar la educación de los niños y adolescentes. En consecuencia, deben inscribirlos oportunamente en una escuela, plantel o instituto de educación, de conformidad con la ley, así como, exigirles su asistencia regular a clases y participar activamente en su proceso educativo. (p.38)

Sin embargo, en nada contribuye la existencia de una normativa si no se cumple. Durante la fase diagnóstica de la presente investigación se identificó la marcada ausencia de los representantes el día 07 del año en curso, estando convocada una asamblea para 700 representantes y solo asistieron 22 .

En esta dirección es evidente la necesidad de apoyo del representante como persona responsable de la orientación y disciplina constante de sus representados, entendiendo que es un 
deber de padres, madres y representantes velar y garantizar por la educación de sus hijos, "inscribirlos oportunamente", en ocasiones tres meses después de haber iniciado clases hay estudiantes sin inscribir puesto que el directivo no puede negarle la entrada a la institución a pesar de no estar inscritos formalmente.

En relación a lo ya expuesto, para introducir las normas de convivencia en el funcionamiento de las instituciones educativas, se precisa que éstas sean acatadas en primer lugar por los adultos entendiéndose éstos, como docentes y representantes, quienes desde su no acatamiento de la norma contribuyen con la anarquía estudiantil y los problemas de convivencia en la comunidad educativa.

Además de la violencia verbal y física fuera y dentro de las aulas; la competencia entre los estudiantes; la frágil relación de los docentes con alumnos y padres, que no va más allá del salón de clases; todo esto habla a las claras de que en el aula no se fomenta la convivencia. De esta manera, la praxis educativa no sólo se contradice a sí misma, sino que convierte sus postulados en un planteamiento teórico y vacío, en letra muerta.

La educación y consolidación de valores sociales relevantes son un desafió permanente y también una imperiosa necesidad para la armonía y la convivencia humana, las nuevas condiciones, las nuevas tecnologías, las formas de educar, no exentas de contradicciones y complejidades crecientes en el ámbito económico y espiritual, abren la posibilidad de formar valores humanos.

Es así como en Venezuela se rige por una serie de normativas legales, que lo sustentan en el tiempo y en el espacio. Entre los cuales se encuentran en orden jerárquicos. Los tratados internacionales, la Constitución de la República Bolivariana de Venezuela (2000), Leyes orgánicas, Leyes, Reglamentos, Resoluciones, Circulares entre otros, que orientan la conducta humana y permiten la convivencia social en armonía.

La concepción política actual supone que el individuo es un elemento de participación que debe ser protagonista de los cambios que contribuyan con su formación y que, además, promueva el mejoramiento social a través de acciones comunitarias. Así lo expresa la Constitución de la República Bolivariana de Venezuela (1999), en diversos artículos pero que, de una mejor manera, aparece sintetizado en el artículo 132, que alude Toda persona tiene el deber de cumplir sus responsabilidades sociales y participar solidariamente en la vida política, civil y comunitaria del país, promoviendo los derechos humanos como fundamento de la convivencia democrática y de la paz social.

Por consiguiente, esta investigación sirve como referente para la elaboración de una teorización respecto al medio venezolano, en cuanto a la convivencia dentro de la escuela, y puede contribuir con la generación de propuestas transformadoras para este caso y para la resolución de situaciones de aprendizaje de una manera participativa y reflexiva. Igualmente puede constituir un aporte para la comprensión de la práctica pedagógica como generadora de modelos susceptibles de ser reproducidos por los sujetos en otros contextos. 
No obstante, al vivir en sociedad, se hace indispensable un orden, un mecanismo que regule la conducta de las personas, de tal manera que se respeten los derechos y libertades de todos por igual, y con ello surgen las normas.

Asimismo, para garantizar que las conductas individuales no afecten el colectivo y la sana convivencia interna, se hace absolutamente necesario en cualquier organización establecer las reglas o normas de conductas que garanticen a su vez el cuidado individual de cada integrante de la comunidad.

En este sentido, Gimeno Sacristán (1992) señala que se tienen que incorporar en la planificación de cada docente acciones que fomenten la convivencia, cultivarlos en las actividades específicas y en los métodos generales de su especialidad, ampliando el sentido educativo de ésta. En ciertos casos, será preciso decidir actividades especialmente dirigidas una convivencia donde la comunicación sea bien vista, para lo cual es conveniente que formen parte de una filosofía educativa y de una metodología que impregne toda la actividad.

La convivencia, en su sentido más básico, es un Vivir en compañía de otro u otros, cohabitar; pero en un sentido más preciso habría que delimitar las condiciones de este vivir para que fuera igual al de otros, esto es, para que sea en realidad vivir con el otro y no a expensas de o simplemente cerca de. Por ello, la palabra convivencia aparece muy frecuentemente ligada al concepto de democracia moderna, la democracia implica siempre convivencia y viceversa.

La educación para la convivencia ciudadana debe, pues, preparar a los jóvenes para que se involucren activamente en la vida cívica y política, participen en la elección de sus líderes y en el control de éstos, así como en la toma de decisiones para la mejora individual y social de las condiciones de vida.

En tal sentido, Carbajal Padilla (2013), señala que el constructo de convivencia se utilizó por primera vez a comienzos del siglo XX para caracterizar la Edad de Oro española, en la que judíos, musulmanes y católicos convivían pacíficamente en el mismo territorio. Así, desde el comienzo, el significado otorgado a la convivencia se vinculó a la organización de una forma de vida pacífica que atendiera la diferencia.

De esta manera, Ortega Ruiz (2013) plantea que el término convivencia hace referencia a la interrelación permanente entre grupos sociales diferentes en un contexto complejo; por ejemplo, las oleadas de inmigrantes hacia Europa o los procesos dictatoriales, de insurrecciones y guerras civiles vividos en América Latina.

En tal sentido, Ortega y del Rey (2003) afirman que el concepto de convivencia tiene un claro significado positivos y se relaciona con los principios básicos de la educación, siguiendo unas normas democráticas en beneficio de todos los que hacen vida en cualquier centro educativo.

Oliva, Montes y Torrellas (2009), señalan que «los retos actuales a los que se enfrentan las instituciones educativas son complejos, pues hay que trabajar en varias direcciones que permitan simultáneamente incrementar la equidad, la eficiencia de las instituciones como 
formadoras del ser e incrementar su calidad y pertinencia» (p. 163). Como fue dicho anteriormente, la convivencia y el clima escolar juegan un rol fundamental en la gestión del conocimiento de los establecimientos educacionales. Por consiguiente, tal como señala Jares (2001), el hecho de convivir significa vivir unos con otros basándose en unas determinadas relaciones sociales y en unos códigos valorativos, subjetivos, dentro de un contexto social determinado.

De esta manera, en opinión de Jares (2001) convivir significa vivir unos con otros basándonos en unas determinadas relaciones sociales y en unos códigos valorativos, forzosamente subjetivos, en el marco de un contexto social determinado.

En este sentido, la convivencia en el ámbito escolar se entiende como el proceso mediante el cual todos los miembros de la comunidad educativa aprenden a vivir con los demás, tal como señala Carretero (2008). Se trataría de un proceso basado en el descubrimiento del otro, en entender y aceptar que nuestro marco de referencia vivencial no es el único posible ni necesariamente el más adecuado, pero sí valioso, en el que el respeto, la valoración de la diversidad y la comunicación adquieren un papel fundamental.

La comunicación denominada no violenta por Monclús (2005) se basa en una práctica del lenguaje que refuerza la actitud de conservar nuestras cualidades de «corazón», incluso en situaciones extremas. Este tipo de comunicación lleva a reconsiderar la manera de cómo se entiende a los demás. Las palabras se convierten en respuestas reflexivas que emanan de una toma de conciencia de las percepciones, de las emociones y de los deseos

El origen de todo conocimiento no es entonces la mente humana, sino una sociedad en un momento histórico y el lenguaje es el medio cultural de aprendizaje por excelencia donde el individuo construye su conocimiento porque es capaz de leer, escribir, preguntar a otros y preguntarse a sí mismo sobre aquellos asuntos que le interesan. De allí que Bolívar (2006), señale que el lenguaje egocéntrico se va segregando del social, a través de su reducción paulatina y concluye con su transformación del lenguaje interno.

Aún más importante es el hecho que el individuo construye su conocimiento no porque sea una función natural de su cerebro sino porque literalmente se le ha enseñado a construir a través de un diálogo continuo con otros seres humanos. No es que el individuo piense y de ahí construya, sino que piensa, interacciona con el medio, comunica lo que ha pensado, y de ahí construye.

En este orden de ideas, Kaplún (1992) sostiene que el proceso de comunicación en educación se caracteriza por ser un dialógico y bidireccional, por lo que implica una comunicación que rompe con la cultura del silencio y se sumerge en el ciclo de ida y vuelta de las palabras; por lo tanto, el esquema tradicional emisor-mensaje-receptor cambia por otro donde el destinatario no solo recibe el mensaje, sino que también lo devuelve, dándose una retroalimentación que enriquece la convivencia escolar. 


\section{Propuesta de innovación educativa}

\section{Fortalecimiento de las normas de convivencia en el plantel para optimizar los procesos educativos}

La institución escenario de estudio fue una Unidad Educativa del Municipio Francisco Linares Alcántara, lo propuesto está orientado al cumplimiento de las normas de convivencia en la institución.

Cabe señalar, que la propuesta de socializar el proyecto de normas de convivencia existente es un primer paso para obtener logros mayores, asociados al cambio de conductas disruptivas en el aula y espacios educativos en general.

Tanto es así que la propuesta pretende impulsar acciones donde todos los miembros de la comunidad educativa se verán involucrados activamente como propulsores el cambio que están necesitando, se involucrará a los representantes, agentes de apoyo indispensable para reorientar la conducta de los educandos en las instalaciones del plantel, ya que si los adolescentes aprenden a desarrollar una apropiada convivencia escolar, serán capaces de trasladar y demostrar una convivencia armónica en otros escenarios.

\section{Fundamentación de la propuesta}

Una propuesta de cambio debe ser persistente, pero, abierta y flexible de manera tal que sea producto de una gestión común entre los participantes, en relación con lo indicado, Esté, (1986) señaló: "La participación activa no es posible y real si los participantes no sienten este proceso como propio. Esto quiere decir que los actores del cambio deber ser y sentirse al mismo tiempo autores y gestores de su curso" (p.13)

Destacando este aspecto se pensaron las actividades involucrando al estudiantado, personal de la institución, representantes y personas de la comunidad. En la primera actividad a ejecutarse se llevarán a cabo mesas de trabajo donde éstos propondrán los cambios que ellos consideran necesarios para las normas de convivencia de la institución, que luego de ser aprobadas todos deberán cumplir para así, optimizar el proceso de enseñanza aprendizaje e incrementar los niveles de tolerancia.

A partir de las apreciaciones anteriores, es válido señalar que un proceso educativo efectivo es resultante de la disposición entre docentes, representantes y educandos a asumir su responsabilidad en el proceso mismo y en trabajar en pro de una sociedad productiva y tolerante donde se respire armonía, estabilidad y seguridad, en oposición a los resentimientos y enfrentamientos que lamentablemente invaden la convivencia venezolana actualmente.

Los autores sugieren como tercera actividad la ejecución de una convivencia, donde se refuercen valores de respeto, solidaridad, amistad y tolerancia fundamentándose en la teoría social de Vigotsky (1998) quien afirma "solo en un contexto social se logra aprendizaje significativo", es así como interactuando con sus compañeros en donde al menos por un día se tenga la plena disposición de cumplir con todas las normas, siendo éste un requerimiento para 
participar en la actividad, ellos apreciarán las mejoras en las relaciones interpersonales y en la productividad del trabajo en equipo en combinación con los docentes de apoyo y muchos de ellos decidirán apegarse a las normas y valores institucionales.

En tal sentido, no hay que descansar en el trabajo por el refuerzo de los valores positivos en el colectivo estudiantil porque según Boy y Pine (1996) "Rehuir la cuestión de los valores es ir a una existencia vegetativa en la realmente no importa el propio funcionamiento, puesto que el hombre está determinado a dejarse caer en una función en la que no puede mejorar ni exaltarse". (p.34)

Evidentemente la propuesta tiene fundamentos que augura señales de éxito en torno a las mejoras de las relaciones interpersonales y por tanto de optimización de los procesos pedagógicos.

El contenido que se presenta a continuación refiere las experiencias vividas como resultado de la ejecución del Plan de Acción.

\section{Actividad Na 01}

\section{Mesas de trabajo entre miembros de la comunidad educativa}

En este sentido y con el fin de garantizar el éxito de las mesas de trabajo (etapa antes) se consideró propicio elaborar una agenda de actividades la cual sería el punto de partida para actuar, asimismo fue necesario hacer la distribución de los invitados por mesas de trabajo, los cuales fueron notificados con antelación al evento. La cantidad de personas distribuidas por mesas fue proporcional con la cantidad de información que se debía consultar, lo que condujo a la elaboración de los formatos para registrar la asistencia y las conclusiones resultantes de la discusión de los artículos de las normas de convivencia propuestas a la comunidad estudiantil. Mientras que fue responsabilidad de los docentes guías de cada sección convocar a los estudiantes y representantes seleccionados para dicha actividad.

Es preciso destacar, que en la fase previa a la ejecución del evento fue necesario reproducir el material de apoyo, así como llevar a cabo una reunión entre las coordinadoras de mesa para conocer, unificar y someter a consenso la agenda de trabajo, así como, para estar en conocimiento del objetivo y la dinámica del evento.

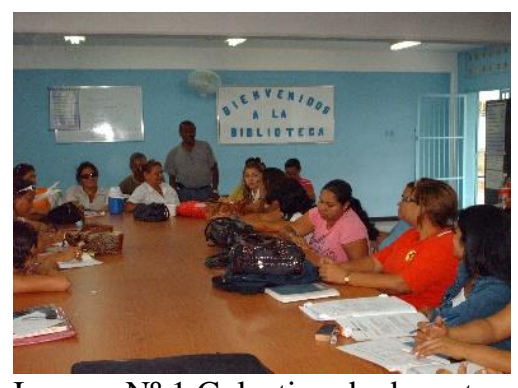

Imagen $\mathrm{N}^{\mathrm{o}}$ 1.Colectivo de docentes. 
A tal efecto, el desarrollo de esta actividad se realizó, el día trece (13) de noviembre, la cual aún y cuando estaba pautada para iniciar a las 3:00 pm, inició a las 3:30 pm en espera de los estudiantes y docentes coordinadores de mesa.

Vale acotar que por causas mayores las profesoras responsables de ofrecer las palabras de bienvenida y cierre invirtieron sus roles según la agenda. La Profa. Estílita Jimenéz encargada de las palabras de cierre dio las palabras de inicio del evento como resultado de una llamada imprevista a la Directora del plantel desde la Zona Educativa de Aragua para que asistiera inmediatamente a una reunión. Seguidamente se hizo entrega del material a cada mesa.

Por lo tanto, para cumplir con las orientaciones, siendo las 4:30 pm se eligió el secretario (a), el relator (a), y el jefe de debate de cada mesa. Es evidente que existe aproximadamente 30 minutos de retraso en comparación con la agenda lo cual se solventó tomando el refrigerio sin dejar de trabajar y disminuyendo el tiempo de participación de cada relator de 10 a 08 minutos durante la plenaria.

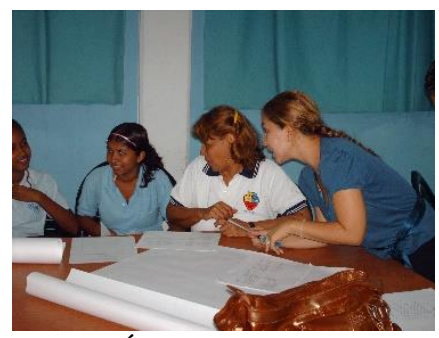

Imagen No 2. Profa. Ángela Marín, autores y estudiantes.

Así mismo, en esta fotografía se nota la participación del Sr. Héctor Rodríguez en nombre de la comunidad junto a los estudiantes y la Profa. Migualida Díaz aclarando sus dudas con respecto al trabajo que debían llevar a cabo.

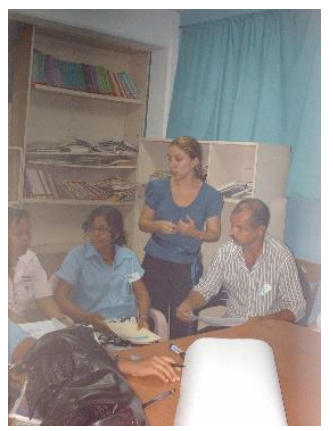

Imagen No 3. Sr. Héctor Rodríguez, Profa. Migualida Díaz y estudiantes.

Consiguientemente se observa como la Profa. Briggite Mora consulta en su diccionario en búsqueda de términos simples para la mejor comprensión de sus estudiantes y específicamente de su relatora Martha que está apoyada viendo la lámina que al concluir deberá presentar representando a la mesa $\mathrm{N}^{\circ} 04$. También aún y cuando no se nota mucho por causa de los globos se evidencia la presencia de la Sra. representante Ada de Padrón quien apoyo la labor de la mesa en todo momento. 


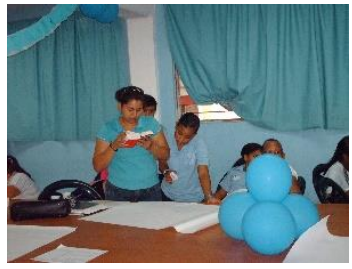

Imagen $\mathrm{N}^{\mathrm{o}} 4$ Mesa $\mathrm{N}^{\mathrm{o}} 04$ buscando términos simples.

En la misma línea, la mesa $\mathrm{N}^{\circ} 05$ coordinada por la Profa. Estilita Jiménez también aporto excelentes ideas propicias a la discusión demostrando disposición para la actividad en todo momento. En ese instante se daban toques finales a las correcciones que desde su óptica debían hacerse al proyecto de normas de convivencia. Esta experiencia se muestra en la gráfica que se presenta a continuación.

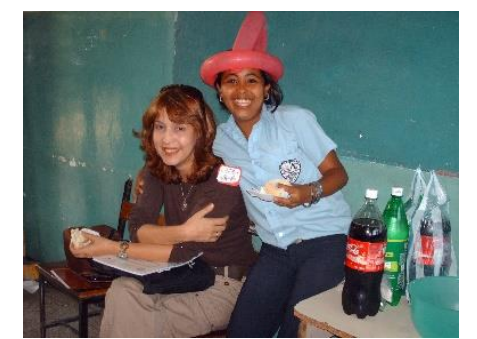

Imagen $\mathrm{N}^{\mathrm{o}}$ 5. Instantes de reflexión.

Siendo las 5:00 pm se observa el entusiasmo con el cual trabajaron los estudiantes de la mesa $\mathrm{N}^{\circ} 04$, con el apoyo de los representantes quienes se encuentran a ambos lados para lograr concluir el rotafolio a tiempo.

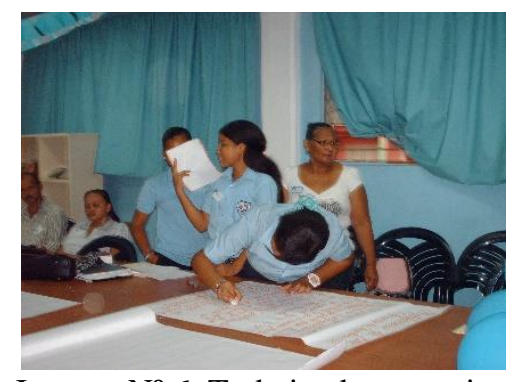

Imagen $\mathrm{N}^{\circ}$ 6. Trabajando en equipo

Es de singular importancia referir que fueron los estudiantes los responsables de hacer públicas las conclusiones y observaciones de la mesa en cuanto al tema tratado, es así, como a continuación se muestra la realidad capturada en imágenes, a través de las fotografías de esos educandos que se despojaron de su timidez para levantarse frente a personas de la comunidad, representantes, compañeros, docentes y exponer con firmeza las consideraciones de su equipo de trabajo.

En virtud de lo expuesto, Roxana Rodríguez se muestra en la fotografía representando a la mesa $\mathrm{N}^{\mathrm{o}} 01$. Entre algunos aspectos señaló “que se permita al menos el uso del celular sin cámara dentro del liceo" en vista que el proyecto de normas plantea lo contrario. 
En concordancia con lo anterior, la mesa $\mathrm{N}^{\circ} 03$ representada por Martha sugirieron siendo muy apropiado para colaborar con las actividades en el liceo y en la comunidad, "No suspender al estudiante siempre, sino, ponerlo a trabajar en la institución, hacer carteleras, elaborar pancartas informativas para la comunidad, apoyar la logística de actividades, entre otras"

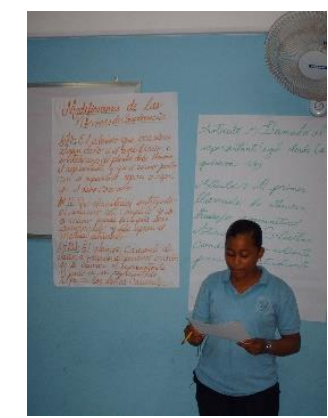

Imagen $\mathrm{N}^{\mathrm{o}}$ 7. Martha Padrón indicando conclusiones.

No obstante, la mesa $\mathrm{N}^{\circ} 04$ también consideró pertinente la aplicación del trabajo comunitario para sustituir otro tipo de sanciones, cabe señalar que por fallas técnicas de la cámara fotográfica no se logró capturar dicho momento.

Considerando lo descrito vale referir que para concluir la plenaria siendo las 5:45 pm Víctor Vellorín relató las apreciaciones de la mesa $\mathrm{N}^{\circ} 05$, recalcando que el análisis realizado y las conclusiones generales del día de trabajo debían divulgarse en todas las aulas mediante actividades socializadoras entre los participantes de las mesas y sus compañeros de aula. De ahí que, se muestre la siguiente gráfica donde el referido estudiante, se observa orgulloso de su rotafolio y exposición.

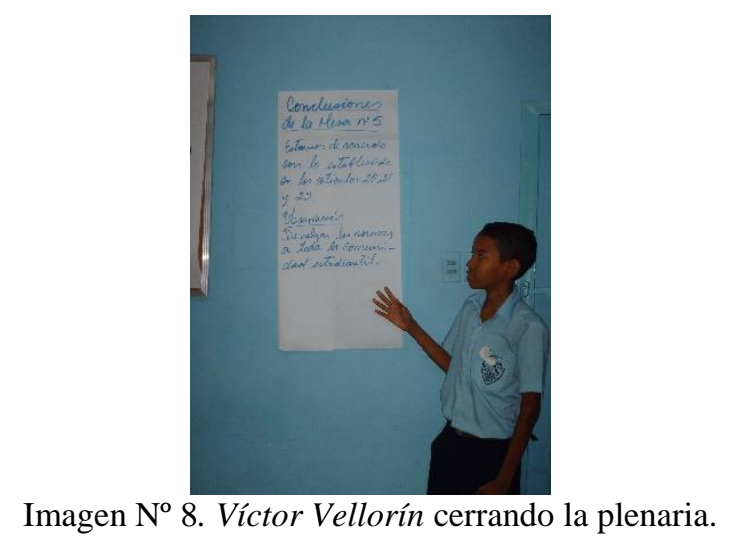

Como etapa de cierre, en este orden de ideas es propicio resaltar el apoyo de los docentes para que dicha actividad fuese exitosa y dejara los resultados esperados, así como contar con una asistencia de 38 personas como se evidencia a continuación.

Consiguientemente, las conclusiones fueron socializadas en todas las aulas y con escasas excepciones hoy más que antes se observa mayor disposición por parte de los educandos para cumplir con las normas institucionales. 


\section{Actividad No 02}

\section{Charla sobre estrategias que faciliten el rol de los padres como rectores en el cumplimiento de las normas de convivencia de sus representados}

Asimismo, se convocó a los representantes y personas de la comunidad. Los docentes guía de cada sección se encargaron de dicha labor. Igualmente fue necesario buscar y reservar con antelación el video bean, en vista de que la institución no lo posee, se organizó un comité de ambientación y refrigerio para delegar funciones entre los estudiantes, los cuales siempre se mostraron dispuestos.

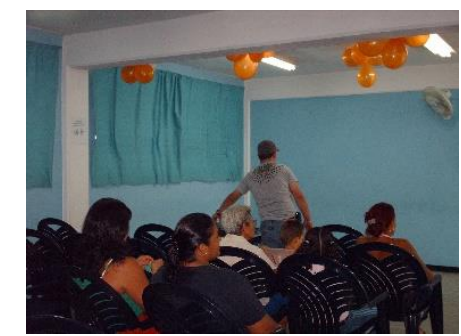

Imagen $\mathrm{N}^{\circ}$ 9. Pruebas del video bean.

De igual manera, se presenta a la autora de la investigación ofreciendo las palabras de bienvenida al público en general en compañía de la Directora de la institución la Profa. Yaneth Cabrera y el Profe. Carlos Azuaje responsable de la charla y especialista en el área.

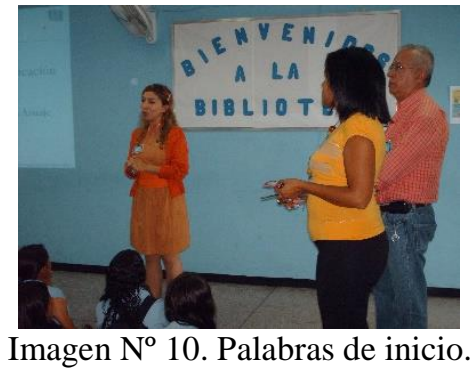

Cabe señalar que las expectativas de concurrencia fueron superadas registrando una asistencia de 44 personas, entendiendo que se convocó a 150 entre convocatorias directas y mediante pancartas a la comunidad en general. Pero, si se compara con la asistencia regular es un éxito rotundo en vista de que se han convocado 650 representantes y han asistido 22. La gráfica siguiente muestra parte de los asistentes al evento.

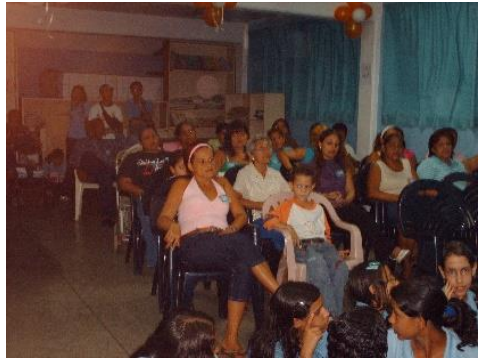

Imagen $\mathrm{N}^{\circ} 11$. Asistentes 
En otro sentido, el audio causó algunas incomodidades durante la actividad como resultado del espacio reducido y la cercanía entre el ponente con el micrófono y las cornetas, como se observa en la imagen.

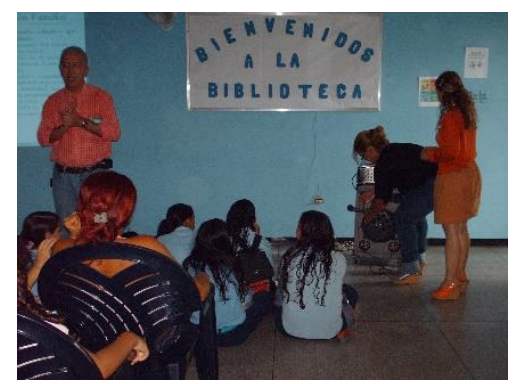

Imagen $\mathrm{N}^{\circ}$ 12. Reparando el audio

Para ocupar en acciones positivas a los educandos asignados a la autora de la investigación durante esa hora de clase de forma regular, se le llamó a la biblioteca para participar del evento y recibir junto a sus padres una información de boca del Prof. Carlos Azuaje que, de ser aplicada, mejoraría la calidad de vida de todos los asistentes.

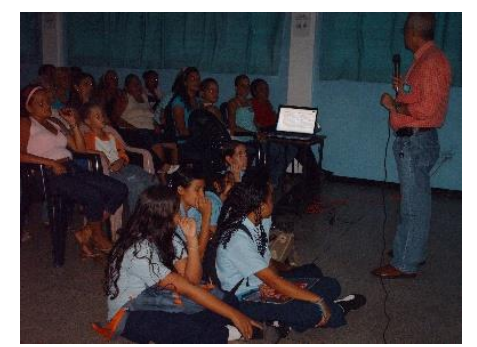

Imagen $\mathrm{N}^{\circ}$ 13. Prof. Carlos durante la ponencia.

Es gratamente oportuno resaltar la valiosa colaboración desinteresada del Prof. Carlos Azuaje quien aún y cundo poseía una agenda copada de compromisos aceptó apoyar la presenta investigación, convirtiéndose en un pilar para fortalecer la convivencia y el cumplimiento de las normas institucionales desde el hogar, siendo, los educandos y jóvenes de la comunidad impulsados por sus padres con las estrategias de la comprensión, el amor y la orientación oportuna para hacer de éstos, mejores estudiantes y a su vez ciudadanos educados y formados para vivir en una sociedad de relaciones armónicas.

Por tal razón se deja registro del profundo agradecimiento que se siente por este docente comprometido en cuerpo y alma con los cambios sociales desde el núcleo familiar, la matriz de las debilidades o fortalezas de nuestra sociedad en desarrollo.

Sin embargo, como etapa de cierre es propicio referir que resulto difícil capturar las apreciaciones de los asistentes, pues al final hubo un clima de silencio, aparentemente se estaba en un estado de reflexión profunda sobre las palabras ofrecidas por el especialista. Al final el profesor hizo hincapié en la urgente necesidad de manifestarles a los hijos o representados el amor que se siente por ellos, pues solo así se fortalecerá el vínculo entre éstos y se incrementará la salud emocional y física de nuestros jóvenes. 


\section{Actividad No 03}

\section{Convivencia estudiantil}

A fin de, completar la ejecución del Plan de Acción diseñado para optimizar el cumplimiento de las normas de convivencia escolar, se llevó a cabo una convivencia entre los estudiantes de 8vo. Grado C, ya que por compromisos académicos del resto de las secciones no era prudente ocupar una tarde para dicha actividad.

Como resultado de lo anteriormente expuesto y centrándose en la (etapa durante), el día 01 de diciembre los estudiantes decoraron el aula, y colocaron los pupitres en circunferencia lo que dio un carácter completamente diferente a un espacio cotidiano ya que todos los días del año escolar éstos, reciben su instrucción académica sentados en sus pupitres de forma tradicional colocados en columnas, uno detrás del otro viendo la espalda de su compañero.

Consiguientemente se presenta una secuencia fotográfica del desarrollo de la convivencia para evidenciar como se ejecutó esta esperada actividad por los estudiantes y todos los que de una u otra forma participaron en ella dando apoyo incondicional. En esta gráfica se observa varios grupos de estudiantes organizados entre tres y cuatro personas haciendo lecturas referentes a la importancia de la convivencia en el entorno social, así como elaborando desde su experiencia un concepto de convivencia.

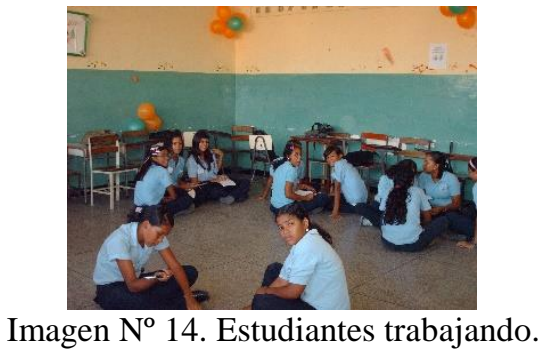

Esta gráfica más que revelar el trabajo que se está realizando, donde se les hacían algunas indicaciones a ese grupo necesarias para avanzar en la elaboración de conceptos evidencia la disposición al trabajo, las expresiones del rostro de los que conforman el cuadro irradian disposición al trabajo y la alegría de jovencitos que quieren vivir en una comunidad tolerante y segura para todos.

En la misma dirección, al finalizar el tiempo de lectura se llevó a cabo una sesión de intervenciones donde desde el juego de la "papa caliente" el elegido debía indicar su concepto de convivencia y la importancia de éste y asociarlo a cualquier palabra, las asociaciones más frecuentes fueron: Amistad. Compartir, compañerismo, confianza, alegría y valores.

Luego del receso se inició la dinámica de cierre de la tarde, denominada "La araña" o "Tejido" donde los estudiantes debían pasar el rollo de pabilo a sus compañeros y decirles una expresión de buenos deseos para el cierre de lapso académico. Al haber concluido cada estudiante de haber indicado su deseo a otro y todos tener una parte del pabilo en mano, se procedió a recoger el mismo, pero, ahora al devolverlo a su compañero para ir enrollándolo de 
nuevo era necesario indicar una expresión de afecto para con el otro, y así al estar enrollado por completo el pabilo, todos habían dado buenos deseos y referido palabras afectivas las cuales en muchos casos fue difícil ofrecer en vista de que aparentemente son jóvenes que no han sido educados bajo modelos afectivos donde el amor, la aceptación y tolerancia no son valores fundamentales.

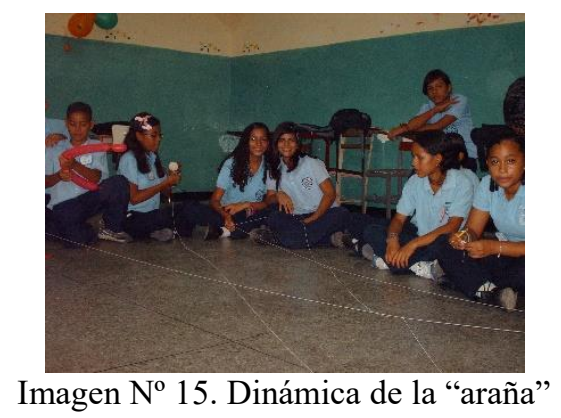

Ahora bien, el fortalecimiento del cumplimiento de las normas de convivencia es tarea diaria de todos los involucrados en el proceso educativo, incentivando la convivencia en armonía y el valor del respeto hacia el otro, pues quienes ahora son estudiantes de la U.E. Creación Santa Rita I conforman un gran número de habitantes de la localidad El Museo CANTV y por lo tanto, forman parte de esa comunidad interactuando diariamente en el acto de la convivencia humana. De tal manera, que cada una de las actividades ejecutadas en el marco del Plan de Acción propuesto en el presente trabajo de investigación son solo un paso y el inicio de un compromiso para seguir trabajando en pro de una sociedad capaz y dispuesta a relacionarse respetando la individualidad del otro al cumplir con normativas comunes.

\section{Conclusiones}

Indudablemente la experiencia fue enriquecedora y sensibilizadora al permitir socializar con la comunidad, ese grupo de personas que son las raíces de nuestros educandos, un contexto amplio y complejo dependiendo de los ojos que lo vean. De tal manera, que se confirma la necesidad de desdibujar los límites de los espacios educativos y abordar las situaciones no deseadas desde su raíz, la cultura de la comunidad.

Así pues, se insiste en que se debe sensibilizar al colectivo sobre la importancia de la convivencia armónica en comunidad, pues solo de esta manera abra tiempo y lugar para fusionar esfuerzos en pro del desarrollo local como base de la estructura nacional.

Por otra parte, nuestras instituciones en su mayoría lamentablemente no disponen de recursos audiovisuales y a veces ni de espacios para la reunión, por lo cual organizar actividades para asistencia masiva genera una gran movilización de recurso humano y financiero lo que en tan poco tiempo resulta una tarea muy dura y desestabilizadora emocionalmente, y por lo tanto, ningún proceso educativo puede ser bien recibido bajo patrones de estricta presión, pero se pueden aprovechar otros medios en beneficio de esa transformación en el contexto educativo.

Se trata de considerar que la comunicación es la alternativa más idónea para mejorar la convivencia escolar, pues no solamente contribuye a la transformación de conflictos en la 
cotidianidad de las instituciones educativas, sino también los previene a partir del diálogo basado en el respeto y aceptación del otro.

\section{Bibliografía}

Bolívar, R. (2006). Vygotsky: Una concepción del desarrollo y el aprendizaje que trasciende tiempo y espacio. ( $1^{\mathrm{a}}$ ed.). Maracay, Venezuela: UPEL

Boy, A y Pine, G. (1996). El consejero escolar. Un nuevo concepto. (1 $1^{\mathrm{a}}$ ed.). Madrid: Nancea.

Carbajal Padilla, P. (2013). Convivencia democrática en las escuelas. Apuntes para una reconceptualización. Revista Iberoamericana de Evaluación Educativa, 6(2), 13-35. Recuperado de http://www.rinace.net/riee/numeros/vol6-num2/art01.pdf [Consultado, lunes 11 de marzo de 2019]

Carretero, A. (Coord.) (2008). Vivir convivir: convivencia intercultural en centros de educación primaria. Granada: Andalucía Acoge.

Constitución de la República Bolivariana de Venezuela (2000). Caracas.

Este, A. (1986). Los maleducados. (2 ${ }^{\mathrm{a}}$ ed.).Caracas: Editora Universidad Central de Venezuela

Gimeno, J. (1992): «Investigación e innovación sobre la gestión pedagógica de los equipos de profesores». En: La gestión pedagógica de la escuela. Santiago: UNESCO/OREALC.

Kaplún, M. (1992). A la Educación por la Comunicación. Santiago de Chile, Chile: UnescoOrealc.

Jares, X. R. (2001). Educación y conflicto. Guía de educación para la convivencia. Madrid: Popular Jares, X. R. (2001).

Monclús Estella, A. (2005). La violencia escolar. Perspectivas desde Naciones Unidas, Revista Iberoamericana De Educación. N. 38 (2005), pp. 13-32. Recuperado de: file:///C:/Users/MariaE/Downloads/rie38a01.pdf

Ley Orgánica para la protección al niño y al adolescente. (1998). Promulgada por el Gobierno Nacional. Caracas: Educen.

Oliva, E., Montes, S. y Torrellas, L. (2009): «Educación en valores para el fortalecimiento de la convivencia escolar en el contexto educativo». Revista Educare, Vol. 15, No2

Ortega, R. y Del Rey, R. (2003). La violencia escolar. Estrategias de prevención. Barcelona: Graó.

Ortega-Ruiz, R., Del Rey, R. y Casas, J. A. (2013). La convivencia escolar: clave en la predicción del bullying. Revista Iberoamericana de Evaluación Educativa, 6(2), 91-102. Recuperado de https://revistas.uam.es/index.php/riee/article/view/3406/3623 [Consultado, martes 12 de marzo de 2019]

Vigotsky, L. (1998). El desarrollo de los procesos psicológicos superiores. España: Visor 